\title{
LA ALIMENTACION ARTIFICIAL EN LA PROTECCION A LA PRIMERA INFANCIA DE LA CIUDAD DE BUENOS AIRES
}

\section{Aspecto económico y social.}

Por MARIO H. BORTAGARAY

Lirector de la proseción a la Primera lafancia de ba ciudad de Buenos Air.s.

En la ciudad de Buenos Aires, el más importante de los organismos de protección abierta para los lactantes, lo constituye la Protección a la Primera Infancia, dependiente de la Municipalidad, formada por veinte Dispensarios de Lactantes y cinco Institutos de Puericultura, repartidos en la ciudad, respondiendo en parte a la distribución de los registros civiles y a la inscripción de nacimientos que en éllos se efectúan.

La atención médica es completamente gratuita, sea cualquiera la situación económica de la familia: no existiendo limitación de número para la concurrencia, tratándose siempre de ampliarlo aun más, por una propaganda intensiva. el servicio social y la Escuela de Puericultura anexa.

$\mathrm{Si}$ bien son múltiples los factores de disminución de ía mortalidad en la capital de la República Argentina que la ha llevado a ocupar el cuarto lugar entre las capitales del mundo se debe esto en gran parte a la acción de la Protección a la Primera Infancia.

Desde su fundación y refiriendo las cifras de mortalidad infantil a cada diez años, se observa un neto descenso; mientras en 1908 era de 96 por mil, en 1918 de 86 por mil. en 1928 de 74 por mil, en 1938 de 55 por mil, alcanza en 1940 al 49.66 por mil.

La concurrencia a la Institución fué en el último año de 21,855 ; los lactantes que pot primera vez se asistieron, corespondiendo a cerca del 50 por ciento de la natalidad de la Capital Federal. que alcanzó en ese periodo a 45,632 racimientos viables. 
Como cada año se presentan los niños de más tierna edad al dispensario, la defensa de la lactancia materna y el alejamiento de la alimentación artificial es posible conseguirlo. Se ha comprobado en 1940 que al iniciarse la vigilancia de los niños, el 55.22 por ciento se alimentaban con el seno materno, el 20.32 estaban a alimentación mixta y el 24.46 con alimentación artíficial exclusiva.

Estas cifras crean el problema económico, higiénico y social, al que se encuentra enfrentada la Protección a la Primera Infancia, para perseverar en la alimentación natural $y$ encarar la alimentación artificial.

Como la asistencia del niño se prolonga durante sus dos primeros años de edad, debemos agregar a los inscriptos por primera vétz, los del año anterior alcanzando en el pasado año a 47.567 los asistidos, de los cuales, una minima parte son alimentados por las cocinas de leche, con raciones preparadas de acuerdo a las prescripciones médicas, término medio, 595 diariamente, número menor que los 1,819 que fueron inscriptos en las cocinas en los dos últimos años, debido a los alejados por diserciones y cambio a la alimentación variada. El aspecto económico y social surge de estos 595 lactantes que por sus condiciones deficientes, económicas y de salud, obligan a una organización de la alimentación artificial racional.

El resto, mucho más numeroso, que se atiende en los dispensarios, se aparta de la posibilidad de sistematización, pues, siendo las familias de condiciones económicas medianas, y aun buenas, sólo reciben los consejos precisos para que los niños sean alimentados artificialmente en sus hoga. res, con más o menos exactitud.

Las raciones preparadas y distribuidas, siempre en el año 1940, aunque en los últimos diez años han oscilado alrededor del mismo número, suman un total de $1.250,396$ frasccs, que equivale a 6 raciones diarias término medio por niño y se entregan en frascos de vidrio de fácil limpieza, en una canasta de alambre; las roturas y las pérdidas no recargan el costo, pues se descuentan de un depósito fijo que - tealiza la madre al comenzar a retirar el alimento.

La Municipalidad de Buenos Aires suministra gratuitamente las raciones de leche pura, con diluyentes a cocimiento de cereales o harinas dextrinomaltosadas y en menor cantidad leches modificadas y agregados especiales, asegurando el suministro regular por licitación pública y contratos con casas comerciales. 
Los alimentos comprados y su costo durante el año 1940, son los siguientes:

Precio unitario

\begin{tabular}{|c|c|c|c|c|c|}
\hline I.eche de vaca $\ldots$. . . ... & .. $\quad 227.797$ & liccos & $\$ 25.401 .10$. & 0.11 & el 'itro \\
\hline Crema de lectre .. .. ... & .. $1.824,250$ & " & ". 3.374 .40 & $1: 85$ & " \\
\hline Cercales . ......... & .. 734,000 & $K_{\alpha}$. & 330.30 & $" 0.49$ & " Kg. \\
\hline Crema de arroz .. .. ..... & 800,000 & , & 600.00 & $\because \quad 0.75$ & $" *$ \\
\hline Harina de trigo $\ldots$.. & 309.000 & ". & 48.82 & 0.158 & $"$ \\
\hline $\begin{array}{l}\text { Harinas del comenio } . . . \\
\quad \text { (envases } 250 \text { a } 375 \text { ars.) }\end{array}$ & 902,480 & $r$ & $\because 3.230 .11$ & 3.28 & $"$ \\
\hline Polvos tipo Babeurre .. .. & $\geq 18.500$ & " & 915.5 .00 & 3.00 & ". \\
\hline Ifeche de vaca (en polvo) & 453,370 & $"$ & " $1,563.82$ & 3.45 & " \\
\hline Leche condensada $\quad \ldots \quad \ldots \quad$. & 258.000 & $"$ & 270.90 & 1.05 & " \\
\hline Sopa de Keller an polvo. & 178.500 & " & 1.050 .00 & 5.88 & $"$ \\
\hline Caseinato de calcio ... .. & 33,000 & $"$ & 544.50 & ${ }^{\prime} 16.50$ & \\
\hline & v & & & & \\
\hline
\end{tabular}

Se deduce del costo de los alimentos utilizados para preparar las 1.250 .396 raciones que cada una de éstas se puede valorar en 3 centayos; este valor es aumentado casi en 1 centavo más por los gastos generales y de combustibles usados $\mathrm{y}$ en $4 / 2$ centavos más por el pago de sueldos del personal empleado en la preparación, pues existen 25 preparadoras y 3 reemplazantes, cuyos sueldos oscilan entre $\$ 165$ y $\$ 180$ mensuales, una para cada cocina de leche ubicadas en los Dis. pensarios e Institutos. La capacidad de producción de raciones, en muchas de ellas, no se halla saturada, por lo cual loz gastos generales y sueldos de personal gravitan excesivamente sobre el costo de las raciones.

Sin embargo, las grandes distancias a que se encuentran uno de otro los dispensarios, por ser de gran superficie la ciudad de Buenos Aires, no justifica la refundición o centralización de las cocinas de leche, idea útil sólo en algunos aspectos, como la preparación de las harinas para la supresión de las envasadas y la posible economía de gastos de personal. La refundición obligaría a utilizar medios de transportes a los concurrentes a las cocinas, con perjuicio para ellos, falseando la acción económica y social a que esta obra está orientada.

Cada lactante cuesta alimentarlo a la Instítución, considerando las 6 raciones término medio, 51 centavos por día. 
La ayuda económica al hogar pobre con un niño en crianza, no es realmente grande, pero considerando la falta de higiene y la falta de instrucción, productos de la pobreza, de esos hogares que se refleja en perjuicio de la alimentación del niño. adquiere la cocina de leche una gran función social, uniendo al lactante más pesitivamente al centro de vigilancia que es el dispensario. Los alimentos controlados por la Institución alaja una cantidad de peligros: con la leche de vaca principalmente, se arbitra una serie de recaudos que aseguran su higiene.

La leche de vaca es barata y abundante en la ciudad de Buenos Aires, por las características ganaderas de la región $y$ los numerosos tambos que la rodean y si bien las condiciones de ordeñe y transporte, salvo algunos ensayos promisores, dejan mucho que desear, puede considerarse su calidad como buena. Su costo, que para la Municipalidad es de $\$ 0.11 \mathrm{~d}$ litro, se expende al público a $\$ 0.15$ y a $\$ 0.20$ la envasada pasteurizada. Estos precios y lo barato de los cereales comunes y harinas de posible torrefacción, crea para los asistidos a los dispensarios, no concurrentes a la cocina de leche, la posibilidad de ser alimentados a un precio bastante bajo, por 1o cual se apartan de la cocina, quedando reservada la entrega de alimentos preparados sólo como una ayuda social económica a las familias de recursos nulos o muy escasos y a indicaciones dietéticas especiales.

La calidad de la leche y su precio, no ha planteado en nuestra capital la necesidad de ser sustituida por leches conservadas o condensadas, problema a encarar en algunas regiones de nuestro extenso territotio.

El continuar la vigilancia de la alimentación artificial en el hogar, tanto en los concurrentes o no a la cocina de los dispensarios, lo considera el Servicio Social de la Proteción a la Primera Infancia, una de sus preocupaciones, tratando de mitigar el peligro alimenticio que la ignorancia $y$ los malos consejos mantienen perenne.

En conclusión, en la Ciudad de Buenos Aires la alimentación artificial del lactante, en su aspecto económico y soçia?, no presta inconvenientes mayores y sólo es dable mejorarlo en pequeños detalles de organización y economía e insistir en una propaganda intensa y racional para no dejar a ninguna criatura sin el consejo o la ayuda oportuna. 